\title{
A Project Based Learning approach for Production Planning and Control: analysis of 45 projects developed by students
}

\author{
Sanderson César Macêdo Barbalho ${ }^{\mathrm{a} *}$, Ana Carla Bittencourt Reis ${ }^{\mathrm{a}}$, Julia Alexssandra Bitencourt ${ }^{\mathrm{a}}$, \\ Maria Clara Leopoldino de Arêa Leão ${ }^{a}$, Gladston Luiz da Silva ${ }^{a}$ \\ aUniversidade de Brasília, Brasília, DF, Brazil \\ *sandersoncesar@unb.br
}

\begin{abstract}
The project-based learning (PBL) approach has been a part of the University of Brasilia's programme from the inception of its Industrial Engineering syllabus. Production Systems Project 4 course is one among eight courses that drive the utilization of PBL approach at the curriculum, the subject of this study, in which we present a set of analyses of the projects developed between 2013 and 2016. The projects involved real-world problems, related to public and private sector enterprises in Brazil's Federal District. The conducted analyses aimed to identify the organizations' profiles and the PPC (Production Planning and Control) techniques which were used to achieve project objectives. Therefore, statistical analyses were performed, such as Correlation Analysis, Cluster Analysis, as well as qualitative documental analysis. The results of this study indicate the profile of external partners that have the highest probability of achieving satisfactory results, as well as the main planning elements which impact the final grades of the projects.
\end{abstract}

Keywords

Active learning. Case study. Production engineering. Production, planning and control.

How to cite this article: Barbalho, S. C. M., Reis, A. C. B., Bitencourt, J. A., Leão, M. C. L. A., \& Silva, G. L. (2017). A Project Based Learning approach for Production Planning and Control: analysis of 45 projects developed by students. Production, 27(spe), e20162259. http://dx.doi.org/10.1590/0103-6513.225916

\section{Introduction}

Engineers traditionally require solid knowledge in science and technology. However, with the advent of the 21st century comes the necessity of promoting skills that are not easily developed within traditional methods of engineering education. Challenges for new engineers involve the development of a systemic viewpoint, and the capacity to interface between the different branches of engineering, as well as the ability to propose and solve complex problems, always considering the constant need to accompany the current trends in the field (Bezerra et al., 2010).

Studies related to teaching methodologies have demonstrated many universities' concerns with regards to traditional methods of education, especially in the engineering field. Traditional teaching methods, also known as deductive approaches, in which teachers motivate their students towards focusing their attention and efforts on exams and tests, have resulted in students' increasing lack of motivation and interest (Tobin et al., 1990; Prince \& Felder, 2006). The focus on specific knowledge, which is relevant primarily for tests and exams have resulted in students focusing their efforts exclusively in obtaining passing grades in these evaluations. It results in individuals that neither fully understand what is being studied, nor the manner in which the knowledge must be actually applied, leading to disappointing levels of learning retention.

The development of novel education practices in the field of Engineering has resulted in universities creating new teaching methods. These institutions are increasingly considering the merits of the practical application 
of knowledge, internalized along the course, and before the program's conclusion. It is seen as essential that engineers develop not only purely technical proficiencies, but also interdisciplinary skills such as cooperation and project management (Taajamaa et al., 2013). In this sense, problem-based learning and project-based learning, both commonly called as PBL, have been widely applied as a teaching and learning strategy (Bassily et al., 2007; Kadlowec et al., 2007; Ras et al., 2007; Gillette et al., 2014; Lin et al., 2014; Jeon et al., 2014; De los Ríos-Carmenado et al., 2015).

In order to improve students' knowledge retention, and better relate theory to practice by adopting a methodology that is focused on the students themselves, beginning in 2009 the University of Brasilia (UnB) has implemented an innovative undergraduate program in Industrial Engineering (Prince \& Felder, 2006; Lima et al., 2012; Zindel et al., 2012). Based on the PBL approach, the course aims to foster graduate students' abilities to handle real world problems through the development of specific projects that encourage a systemic and professional interaction with several different environments.

According to Zindel et al. (2012), the proposed approach promotes students' learning by means of assisting an external third party with their internal improvement projects. External partners, as pubic or private companies, will typically propose problems that are handled by course students in a group setting. These real-world case studies are developed through a project-based approach, where planning and execution are graded separately, in order to verify the undergraduates' capacity to apply technical knowledge on these authentic situations. In this context, this paper's goal is to present the results of the PBL approach in one specific course, termed Production Systems Project 4 (PSP4). This course is taught in the same semester as the program's Production Planning and Control course.

In the next section, theoretical concerns are presented. Secondly, the research methodology is described. Section four presents the case study, concluding with a discussion of the results and, finally, several remarks related to the main elements of the study are highlighted.

\section{Problem-based learning}

Teaching approaches based on PBL have been widely employed as a way to develop students' skills, through the practical application of academic concepts learned from real-world situations, throughout a University's program (Soares et al., 2013).

The use of active learning approaches has been the subject of many studies that seek to demonstrate it value in improving students' outcomes. Aalborg University has presented an important example of the implementation of educational models, and has been the object of relevant attention. In 1974, Aalborg University was founded using a combination of a problem-based and a project-organized approach (Kolmos et al., 2004). There is evidence that this university is ranked as one the top institutions in developing engineering education in Northern Europe, in accordance to both the needs of the labour market and its extensive PBL environment (Zhoua et al., 2014).

According to Balve \& Albert (2015), the PBL approach increases individual motivation, and introduces students to actual demands that need to be managed. In this approach, the student transitions from a passive role, in which he or she receives knowledge, to a more active stance. This serves to anticipate future employment experience, by associating classroom theory to authentic professional practices (Ríos et al., 2010).

In the PBL approach, students develop their knowledge through active learning, interactions with the external environment, and independent or collaborative teamwork, with the accompanying guidance of the course's faculty (Taajamaa et al., 2013). According to these authors, in this approach students are not merely passive recipients of knowledge. They are immersed in an experience that is similar to what they will face in their professional life.

When the project-based education includes the whole curriculum, it is used to be called of Project-led education (PLE) (Lima et al., 2007; Crosthwaite et al., 2006). An important use case of this approach is the program of Industrial Design Engineering at the University of Twente. In this program, the students are experienced in working as a group, with four projects per year, in the first and second year of course (Damgrave \& Lutters, 2016).

The PBL approach begins with the accomplishment of one or more tasks that lead to the development of a project scope, which results in a report that summarizes the procedure that was applied (Prince \& Felder, 2006). According to Thomas (2000), PBL projects can be based on one or more thematic units. Through this manner of knowledge construction, it is observed that learning could foster students' motivation and provide them with a greater sense of satisfaction (Frank et al., 2003).

Literature suggests that the qualities related to the competencies learned from PBL are (Bassily et al., 2007; Kadlowec et al., 2007; Ras et al., 2007; Gillette et al., 2014; Lin et al., 2014; De los Ríos-Carmenado et al., 2015; Miranda, 2004): 
- The ability to obtain knowledge that can be used in a professional environment;

- The ability to develop skills used in extending and improving such knowledge;

- The ability to expand problem solving skills.

The use of multiple subjects in an engineering education provides different perspectives regarding several issues, with the study of topics aimed at developing communication skills and teamwork, as well as the ability to solve real-world problems (Aquere et al., 2012). Therefore, PBL is considered as being an approach that can assist in the development of skills and competencies that are now understood as being essential to an engineer's background (Taajamaa et al., 2013).

There are various studies on the use of the PBL approach. The results, with regards to improvements in learning, have been seen as positive for the universities themselves, and have resulted in increasing retention rates for students in various programs (Ragusa \& Lee, 2012). Likewise, the experience acquired by students in the application of technical knowledge in real-world problems have resulted in other benefits, such as improvements in their project planning skills and abilities related to leadership, communication and teamwork (Dym et al., 2005; Coyle et al., 2005).

In a problem or project-based learning methodology, the development of competencies requires the application of technical knowledge in specific contexts linked to the professional practice. This learning methodology, linked to the development of technical and transversal competencies, requires the application of skills that can be characterized as "How to do", that is, it is necessary to apply knowledge in practical contexts (Soares et al., 2013). According to Project Management Institute (2013), the main "soft competencies" for success in carrying out projects are: leadership and influencing, team building, motivation, communication, decision making, political and cultural awareness, negotiation, trust building, conflict management, and coaching. All of them are subtly interrelated, and even difficult to manage separately.

It is important to note that much of current research explores students' own perspectives regarding the improvements seen by learning through solving real-world problems using the PBL approach (De los Ríos-Carmenado et al., 2015; Ras et al., 2007). In this particular research, in spite of considering the development of transversal competencies by students, greater emphasis is being given on studying the impact of the projects' technical characteristics on their outcomes, as well as analyzing the aspects of the project planning process over the results achieved by students.

\section{Methodology}

This research utilizes a case study approach (Yin, 2010) in which a deeper analysis is performed with regards to an object of investigation, which in this case is a PSP4 course structured according to the PBL approach. It was based on qualitative and quantitative data, the latter obtained by means of analyzing grading sheets, and the former by registering the reflections of the course's faculty, who are also the authors of this study. These reflections were used for understanding the results of analysis in form to triangulate data.

Documental analysis (Dane, 1990) was also performed, by first evaluating all final reports and presentations, in order to identify the specific technical knowledge which was applied, and also to characterize both the assisted company and the particular problem which was addressed.

The grading sheets stored data from the first semester of 2013 until the first semester of 2016, totaling 45 projects, with each semester generating a specific sheet. These were analyzed and formatted, being consolidated into a single document containing all projects and their respective grade summaries. As more accurately described later, the students' overall project grades were composed from a weighed average of the grades from their Preliminary, Intermediate and Final reports.

The qualitative data from this documental analysis was inserted into a different dataset, in which a binary classification was considered for each technique used by the project teams. Namely, "1" when the technique was used, or "0" when it was not. This classification was performed by means of a deeper analysis of students' reports. If the report did not mention the technicque, or if it lacked demonstrable results, it was not considered as compliant, and was given the classification "0". A statistical analysis was then conducted regarding the techniques of the anchor course that served as a basis for the developed projects.

Eventually, a new dataset was created based on data from the two previous sets. This dataset was used for the application of deeper statistical analysis using the $\mathrm{SAS}^{\circledR}$ software, such as Correlation Analysis and Cluster Analysis. The objective of this analysis was to characterize the companies used to develop the projects, by providing information about their context. Other objectives included the discovery of the correlations between 
the planning steps and grades, as well as the indentifcation of the techniques that were useful in solving the problems presented, also in order to relate them to the final grades.

The last step was to register the data according to the principles related to operations planning and control, project management and active learning. Qualitative data, gained from the experience of the course's faculty were used in order to reflect discovered significances and correlations.

\section{Case study}

In the University of Brasilia's Industrial Engineering program, the PBL approach is drove by a set of disciplines called production system project (PSP). Each PSP course is related to one or more anchor course in a specific semester, and projects are carried out in accordance with the theme of their respective anchor courses, involving the discussion of practical problems from external agents, with a support of specific project management methodologies used in order to solve them (Figure 1). This approach stimulates students' learning by offering them the opportunity to search for solutions and project proposals aimed at addressing the issues of external agents. No related content is presented to students before each PSP course. Their anchor disciplines are ministered alongside a co-requisite course, and as deeper concepts and techniques are scheduled for the last classes, students commonly utilize self-learning as a method for achieving project solutions.

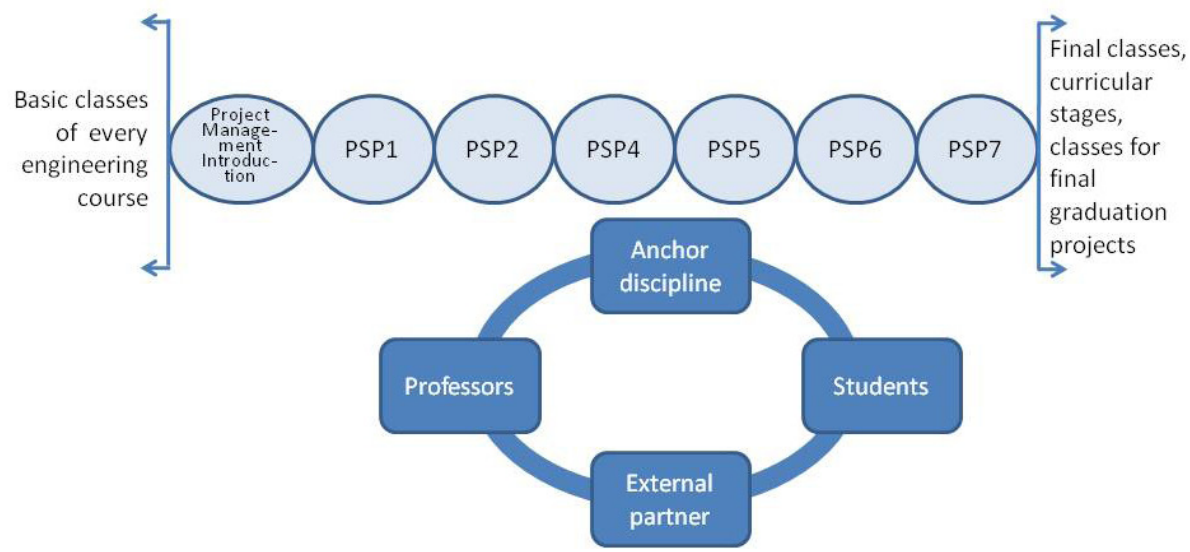

Figure 1. General structure of the University of Brasilia's Industrial Engineering program.

The PSP4 course is related to Production Planning and Control (PPC) discipline, as a co-requisite. The PPC course in the University of Brasilia's Industrial Engineering program is a unique discipline, where students review production system design methods according to Slack et al. (2009) as well as theories related to demand forecasting, capacity planning, inventory management, scheduling and shop floor control (Sipper \& Bulfin, 1997; Vollmann et al., 2004). Although students in the PPC course are tasked with reviewing real-world companies, the course's main focus is theoretical. The professor assigned to PSP4, who commonly also ministers the PPC course, advises students in the implementation of effective actions aimed at solving a real-world PPC problem, as presented by external partners.

The PSP4 course is structured around the assessment, by faculty, of the work accomplished by students, as presented in Figure 2.

The PSP4 course grading structure consists of three grades, in which students are assessed based on the quality of the work presented. The first grade is related to the Preliminary Project (PP) and consists of the evaluation of the Project Management Plan (PMP). This plan is evaluated according to the PMBOK Guide's five areas: Scope, Time, Communications, Stakeholders and Risks. Students are instructed to develop a project plan using the sequence established by the PMBOK Guide ${ }^{\odot}$, in which the Work Breakdown Structure (WBS) consolidates the scope, serving as a basic input for the preparation of the schedule and other technical elements of the project plan (Project Management Institute, 2013). 


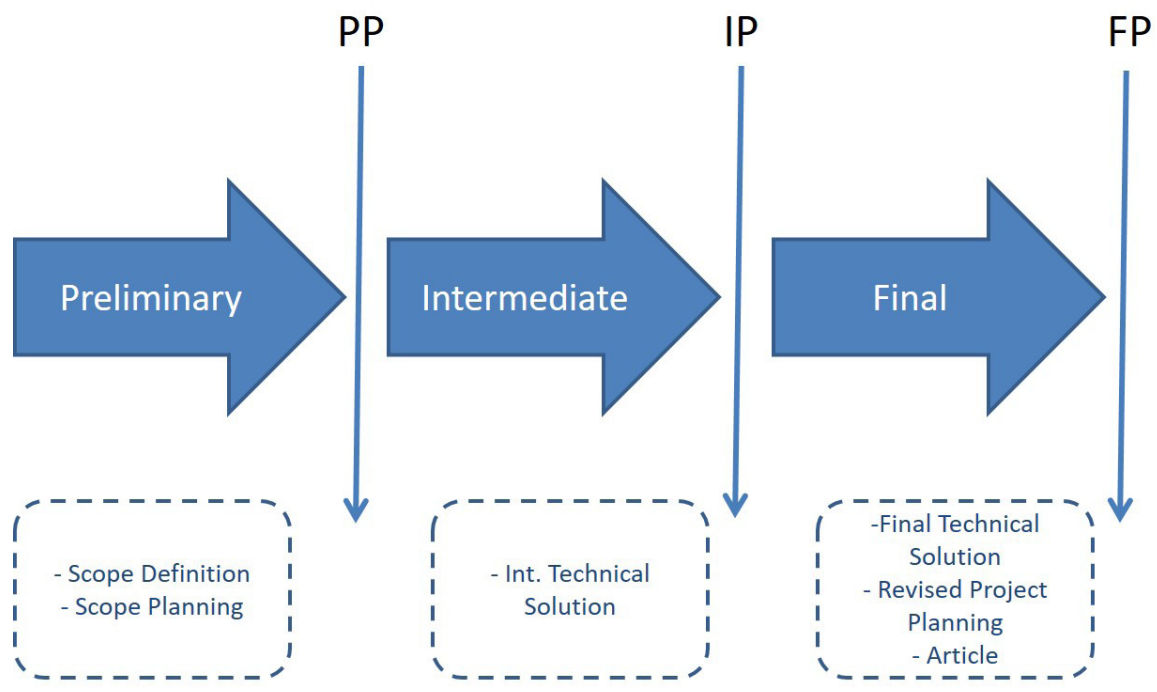

Figure 2. PSP4's basic grade structure.

As the Production Systems Project course is presented as a co-requisite to PPC, meaning that students do not yet comprehend all the contents that can be applied to a specified problem, it is emphasized that the main output of this step is a well-defined scope. In each presentation, professors are able to correct specific mistakes which students can commit when planning their tasks without having had any previous classes in pre-requisite subjects.

Other PMBOK areas are not reviewed, in order to avoid an over emphasis on planning and a lack of focus in solving the external partner's problem.

The second grade is assigned to the students based on the Intermediate Project (PI). While the Preliminary Project focuses on the project planning stage, involving the definition of its scope, schedule, and risk analysis, the objective of the $\mathrm{Pl}$ is primarily to observe the technical development of the tasks, in relation to the initially proposed scope. Therefore, if the project has a purpose of, for instance, analyzing the alignment of the company's share price with its' external demands, the Intermediate Project must present the use of inventory analysis techniques, such as a Pareto analysis, the identification of inventory costs per unit, demand analysis, and identifying trends and randomness, depending on the previously defined scope. The students' presentations form the basis of the Intermediate Project's grade, with the subsequent evaluation made according to students' answers to technical questions posed by the professors over the course of the presentation. As already mentioned in relation to the Preliminary Project phase, in this case professors also give their support in solving problems arising from misunderstandings by students who have not yet attended the previous PPC classes in PPC course.

The normal interval between the Preliminary and Intermediate Projects is of approximately five weeks. During this period, the professors oversee each group's work, advising them over data collection and analysis techniques. In some cases, teachers work jointly with the teams, in order to solve issues related to data gathering or communication pitfalls. If necessary, professors will advise students with regards to mandatory changes in scope, according to projects' deployments.

The Final Project (PF) consolidates the assignment based on the elements developed in the Preliminary and Intermediate phases. As for the PP, the project plan is also analyzed. In this case, students must indicate the differences between the initial plan and the outcomes. As such, the last version of the project's scope is compared to the initial version. The same follows for other elements, such as the project's schedule, communications and risk planning, and stakeholder definitions. It is required that students present a comparison of the changes made between the preliminary delivery's baseline and the project's final configuration. However, the main result of the final project is the content of the technical assignment executed by the project teams. In this sense, the concepts of Production Planning and Control are thoroughly analyzed and compared with the results achieved by the project teams. Concurrently with the final Project, the PPC class is, at this point, concluding its activities. All of the students' coursework has already been reviewed in class, (and the final PCP test might already have been administered), which facilitates the technical discussion of the results. In addition to the revised project plan, students compose an academic article, detailing the technical tasks performed for the external partner. 
To conclude, the Final Project presentation is given in the presence of the external partner, which reflects on the overall results, in the presence of both students and the course's professors, with the resulting feedback being incorporated into the final evaluation.

The schedule of the PSP4 course's final project is sometimes postponed, in order to ensure the quality of the work submitted. There is a usual interval of four to five weeks of activity between the Intermediary and the Final Project, during which the faculties monitor the students' tasks, and eventually work directly with the teams and external agents towards facilitating data collection, analysis, technical applications, and in formatting the final delivery for the external partners.

\subsection{A review of concluded PSP4 projects}

the psp4 course has been ongoing from the first graduate class of the university of brasilia's (unb) industrial engineering program, starting in the second semester of 2012. data from the first semester's class was not considered, as the course's structure was at that stage not consolidated in the manner shown in the previous section. considering the period from 2013's first semester to 2016's first semester, seven psp4 courses were undertaken, totaling upwards of 204 students who have accomplished the activities previously detailed. overall, 45 projects were analyzed. Figure 3 presents the profile of the organizations that participated as external partners during this period.

\section{Types of organization}

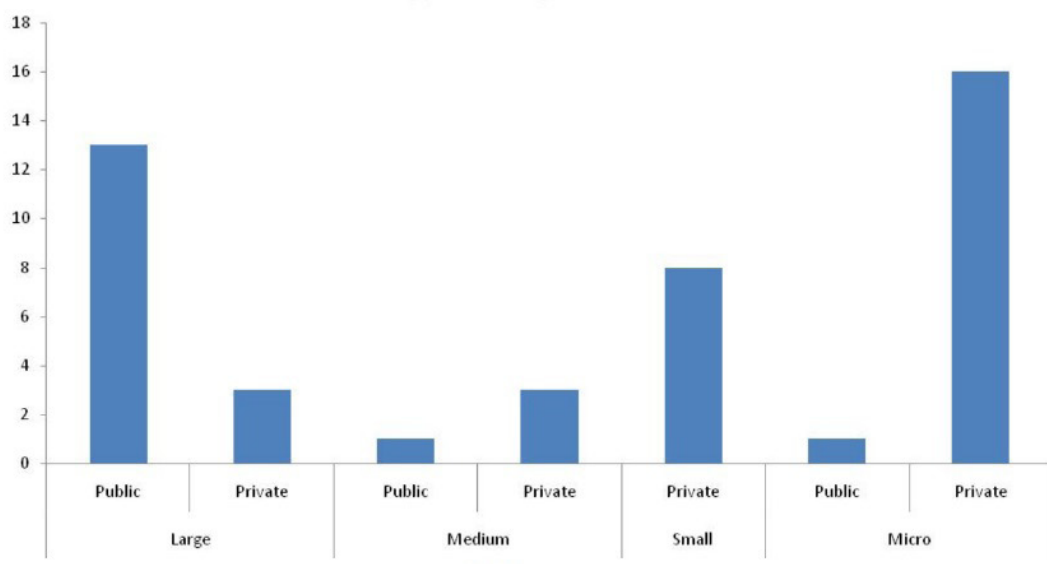

(a)

\section{Types of organization}

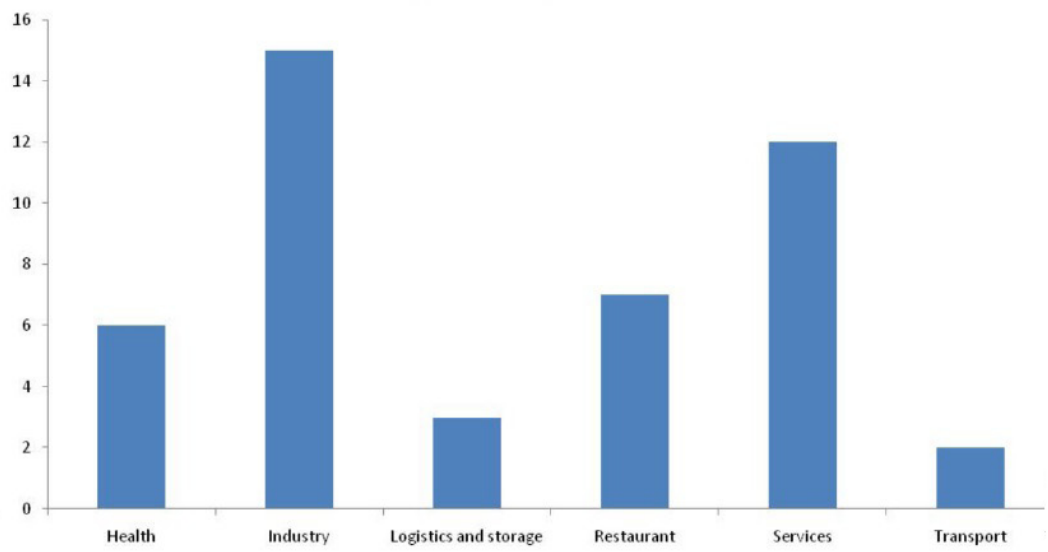

(b)

Figure 3. Classification of external partners of the PSP4 course: (a) size and profile; (b) economic sector. 
Figure 3 presents the characteristics of the organizations that participated in PSP4 course projects. The entities are classified as public or private, and according to their size. It is observed that most assisted organizations are private, corresponding to 30 projects, while public organizations are linked to 15 projects. The data also demonstrates that most participating public organizations are classified as "large", containing more than 500 employees, while private organizations were mostly composed of very small or small enterprises, with up to 10 and 100 employees, respectively.

The analysis of the organizations' economic profiles was conducted according to a classification of goods and services provided. However, as some subcategories were most common, it was considered more appropriate to present the data separately. Thus, Figure $3 \mathrm{~b}$ demonstrates the preponderance of projects related to the service sector, rather than the industrial field. The most representative service sectors are those related to healthcare - in this case, consisting of public hospitals in the Federal District -, and transportation. The Figure also highlights the storage logistics and restaurant subsectors, which are both classified as services, although they do offer aggregate value in which the delivered product is considered as a key component of customer service.

Other service sectors contemplated in the finished projects are those related to tutoring, document management, recycling, car dealerships, medium-sized supermarkets, gas stations, and food transportation. The industry classification is also comprised of various subsectors, such as metal-mechanical, pharmaceutical, food preparation, factories, footwear, medical and dental products, and beverages.

As described in the methodology, the projects were analyzed in order to characterize them in accordance to the utilized production planning and control techniques, as well as the main contributions of the project to the organizations, as required by their owners. The graph in Figure 4 presents the techniques used in the evaluated projects.

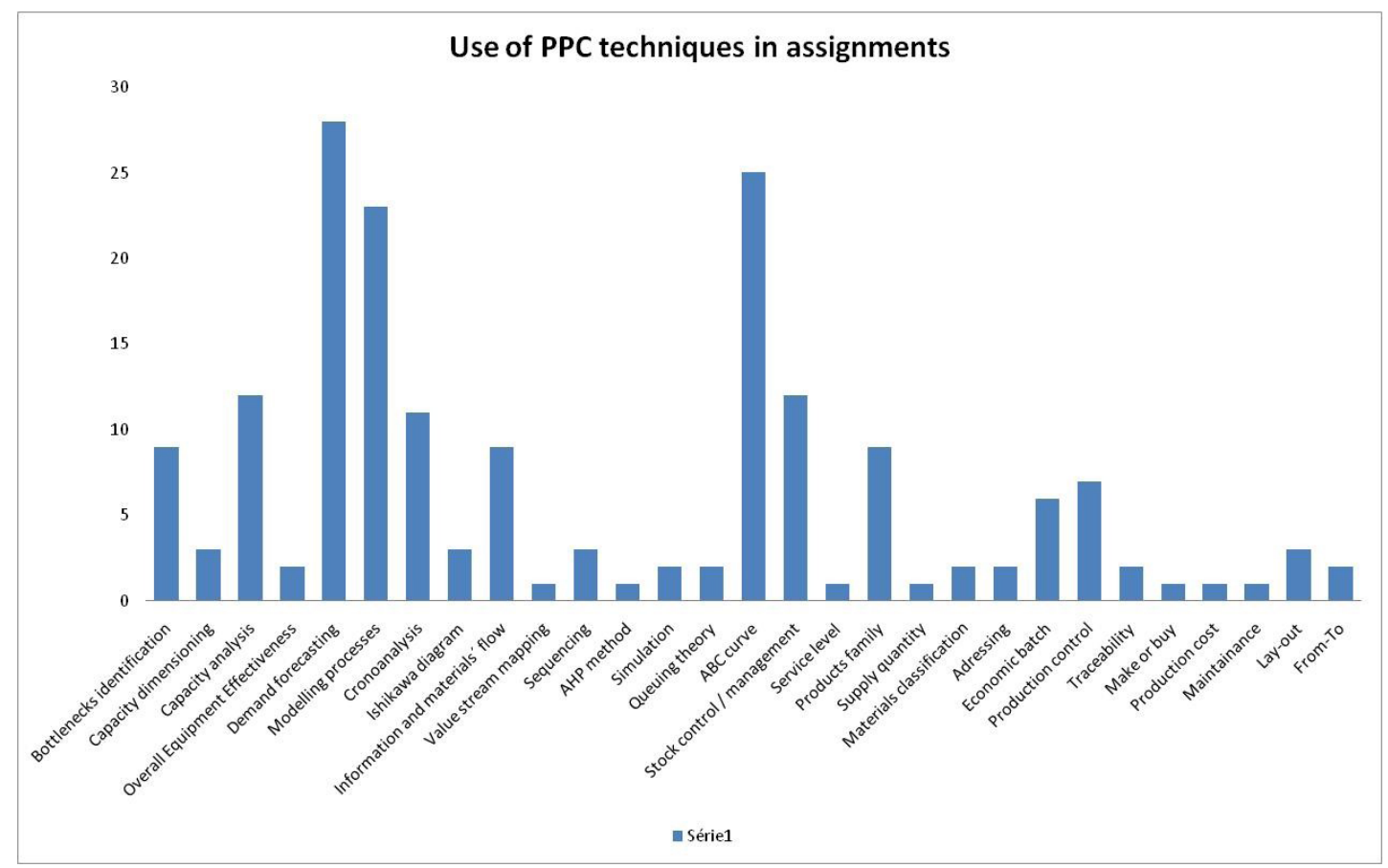

Figure 4. Use of PPC techniques in assignments.

The main techniques used in the assignments are demand forecasting and $A B C$ curves. The projects usually focus on the analysis of the companies' production data, which justifies the application of these techniques. The basic data is related to production demand, and the main analysis has, as its objective, the identification of the company's main products, in terms of volume, revenue or costs. Process modelling techniques are also heavily emphasized, with a predominant use of qualitative methods for analyzing production processes (such as mapping techniques), although several projects have been done based on data analysis. Quantitative data such as measuring the time elapsed in each manufacturing process - were collected throughout the production process, especially in cases in which capacity evaluation and planning was the teams' focus. 


\subsection{Grades attributed to projects}

The consensus among those who experience active learning holds that the grade is not as important as the process of working in teams, and the opportunity to interface directly with real clients (De los Ríos-Carmenado et al., 2015; Ras et al., 2007). In essence, a grade is a summary of the evaluation that professors attribute to projects, according to their results. As such, initial analyses were conducted regarding the projects' grades. The first of these serves to relate the given grades to some of the characteristics of the external partners themselves.

Despite of the fact that PSP4 projects are performed in teams, the grades are individual for each student. Two faculty members share the process of assigning grades in order to reduce subjectivity. The overall results have been positive for student development. From a group of 204 incoming students, only 11 failed the courses, representing $5.4 \%$ of the total.

However, individual grades have mostly been used as stimuli for students' efforts. The actual effective result is tied to the outcomes from each team. Consequently, in order to analyze data from PSP4 courses, only the overall team grades were considered, not withstanding the merits of peer evaluations and individual grades. Figure 5 presents the general grades $(\mathrm{GG})$ assigned to projects developed during the courses.

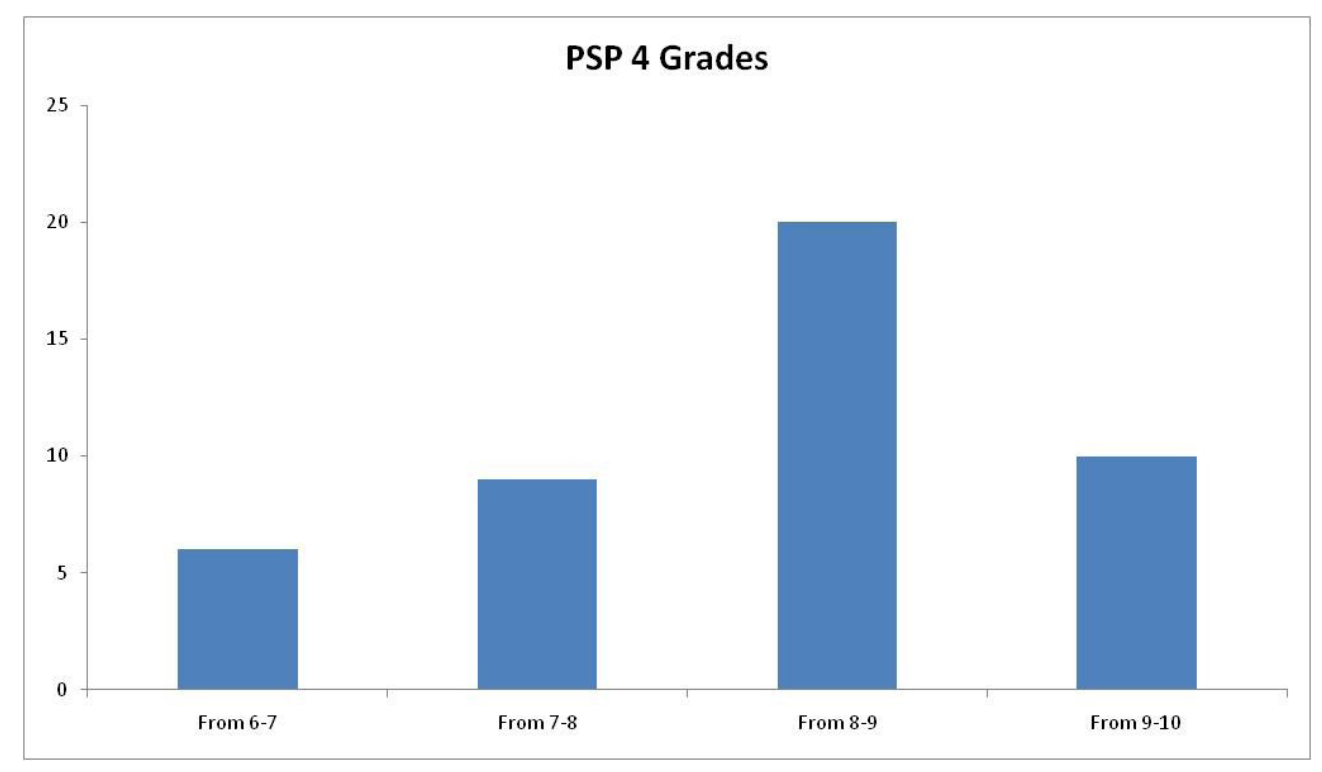

Figure 5. General project grades.

Of note in Figure 5 is the fact that the majority of assigned grades lie between 8.0 and 10.0, falling short of the excellence level, represented by grades 9.0 to 10.0. Additionally, there were no grades below 6.0, which denotes the high standard of PPC applications performed by student groups. Table 1 presents the distribution of the highest scoring projects, according to the characteristics of the organizations presented in this topic.

In accordance with their size, better results were observed in very small or small organizations. Only two out of ten cases with the highest grades were related to large ou medium-sized businesses. This result may be related to the hindrances that large companies possess in transferring the considerable amount of data that must be available for students participating in projects similar to those in PSP. Smaller companies, lacking such levels of bureaucracy, can be more agile in providing data for academic projects. This same factor may be used to explain the fact that eight out of the ten most successful cases occurred in private organizations. Public organizations must usually offer their services for a large number of users, which results in their larger structures. Specifically, bureaucratization is a common characteristic of public organizations in Brazil.

As can be seen, Table 1 also presents the related economic sectors of the external partners in the most successful projects. Four were performed in the industrial sector, only one in the general services sector; three were performed with restaurants, and two in the healthcare field. A deeper analysis of projects related to restaurants and services reveals aspects involving materials planning and control. In this distribution, all cases of projects involving restaurants focused on inventory management, and at the single service company, a capacity planning study was performed, related to service operations at an automotive center. 
Table 1. Grades From 9.0 to 10.0, according to external partners' characteristics.

\begin{tabular}{cccc}
\hline Size & Public or private & Sector & Grades \\
\hline Large & Public & Healthcare & $9.0-10.0$ \\
Small & Private & Industry & $9.0-10.0$ \\
Small & Private & Services & $9.0-10.0$ \\
Small & Private & Industry & $9.0-10.0$ \\
V.Small & Private & Industry & $9.0-10.0$ \\
V.Small & Private & Industry & $9.0-10.0$ \\
Median & Public & Healthcare & $9.0-10.0$ \\
V.Small & Private & Restaurant & $9.0-10.0$ \\
V.Small & Private & Restaurant & $9.0-10.0$ \\
V.Small & Private & Restaurant & $9.0-10.0$ \\
\hline
\end{tabular}

In fact, only two of the most successful cases were truly related to service activities, both in hospital settings. This could mean that industrial activities and service operations involving material flows are, effectively, easier to approach with regards to the application of production planning and control techniques. There could also be a relation to the relative ease, in these cases, of visualizing the production process as a value-added chain, and even in identifying process standards and gathering data in a more objective manner. On the other hand, in service operations, it is often seen that the organization's decision makers themselves do not realize they are producing a service, or in what manner they are able to control the information resulting from their services. In a hospital setting, however, human lives are often at stake, and technicians and professionals that are more skilled oversee all tasks. They are commonly specialists in their respective fields, thus probably exhibiting less difficulty in visualizing their process workflow. These explanations can serve to somewhat clarify the resulting data, but would be better served by an evaluation in future works.

Looking qualitatively at the projects graded 9.0-10.0, as stated on Table 1, a profile of highly focused students becomes evident. These cases show groups in which frequent student engagement was observed. These students typically put forth greater effort in anticipating content not yet presented in the classes of anchor disciplines. This observation will be discussed further on, although a more in-depth analysis of the profile of students is beyond the scope of this article.

The next section presents a statistical analysis of the projects' results, in terms of both their grades and in relation to PPC techniques and project management practices.

\subsection{Statistical analysis}

In order to evaluate the relationship between the variables mentioned in the previous topics, an initial bivariate analysis was performed, followed by a multivariate analysis aimed at identifying homogeneous groups and understanding their characteristics.

In essence, the data was collected from the grades resulting from the PSP4 projects' final scores, as already presented. The grades were initially analyzed in relation to each other, in order to verify which elements were most influential in determining the final grade.

The relation between the grades of the Preliminary, Intermediate and Final phases is purely mathematical, because of the weighted relationship between the grades earned during the semester and the final evaluation grade.

However, the grades that make up both, the preliminary project (which is comprised of the scope, schedule and other planning aspects) and the final scores, are not initially clear. As their influence is the result of several calculation steps, which do not facilitate the perception of correlation, especially when in relation to projects with a variety of themes, organizations and techniques. In fact, there was also a need to analyze the correlation strength between the Primary, Intermediate and Final grades.

Ultimately, the data in Table 2 represents the correlation between the grades. The Table's data corresponds to the following: N1 represents the Project Planning Grade, composed of the N2 to N6 grades, which correspond respectively to the scope, time, communication, stakeholders and risk planning components. N7 represents the Intermediary Project grade, N8 the Final grade, with NG representing the General Grade of the project.

Analyzing the impact of the project grades at the end of the semester and the final score, it is evident that all the correlations are strong, with the highest correlation between all factors $(r=0.85121)$ occurring between the Intermediary Project (N7) and the General Grade (NG). 
Table 2. Correlations between the $N_{1}$ to $N_{8}$ grades and the total grade.

\begin{tabular}{|c|c|c|c|c|c|c|c|c|c|}
\hline & N1 & N2 & N3 & N4 & N5 & N6 & N7 & N8 & NG \\
\hline N1 & 100.000 & $0.85541^{* * * *}$ & $0.77438^{* * * *}$ & $0.49983^{* * * *}$ & $0.67207^{* * * * *}$ & $0.84629^{* * * * *}$ & $0.64630^{* * * * *}$ & $0.44299^{* * *}$ & $0.73546^{* * * * *}$ \\
\hline $\mathrm{N} 2$ & & 100.000 & $0.72881^{* * * *}$ & $0.28369^{*}$ & $0.57552^{* * * * *}$ & $0.67531^{* * * * *}$ & $0.53959^{* * * * *}$ & $0.34383^{*}$ & $0.65107^{* * * * *}$ \\
\hline N3 & & & 100.000 & 0.16283 & $0.38741^{* * *}$ & $0.69495^{* * * * *}$ & $0.48166^{* * * *}$ & $0.37012^{*}$ & $0.55490^{* * * * *}$ \\
\hline N4 & & & & 100.000 & $0.79848^{* * * * *}$ & $0.29286^{*}$ & $0.31686^{*}$ & 0.23878 & $0.42612^{* * * *}$ \\
\hline N5 & & & & & 100.000 & $0.46317^{* * *}$ & $0.37369^{*}$ & $0.31450^{*}$ & $0.53098^{* * * * *}$ \\
\hline N6 & & & & & & 100.000 & $0.63907^{* * * *}$ & $0.38571^{* *}$ & $0.63402^{* * * * *}$ \\
\hline N7 & & & & & & & 100.000 & $0.55595^{* * * * *}$ & $0.85121^{* * * * *}$ \\
\hline N8 & & & & & & & & 100.000 & $0.82793^{* * * * *}$ \\
\hline $\mathrm{NF}$ & & & & & & & & & 100.000 \\
\hline
\end{tabular}

$\left(\right.$ Prob $>/ r /$ under $\left.H_{0}: \rho=0\right)$; Note: ${ }^{*} \mathrm{p}<0.10 ;{ }^{* *} \mathrm{p}<0.01 ;{ }^{* * *} \mathrm{p}<0.005 ;{ }^{* * * *} \mathrm{p}<0.001$.

It could be hypothesized that, considering the grading chronology, the nearest grade (N8) would have the highest correlation no NG, due to students' attempts to achieve a positive result, as the "student syndrome" is reported in project management literatures (Goldratt \& Cox, 2014). Although there is in fact a strong correlation between N8 and NG ( $r=0.82793)$, this correlation is lower than the one between N7 and NG, which illustrates that the Intermediary Project phase is the most representative in terms of the projects' success rate. Additionally, this could be related to the fact that the project team does not possess, at the Intermediate stage, full knowledge of the techniques related to the anchor course. Therefore, the performance at this stage often depends on the student's initiative in seeking to study the content of the lessons before they are presented in classes, as the project's timing is different from the anchor course's schedule. This occurs due to the fact that the strategy adopted by the Industrial Engineering major creates a co-requisite relationship between the PSPs and anchor courses, as opposed to a pre-requisite, system.

In fact, professors have observed that, every semester, the highest-rated projects are those in which the students actively anticipate the classes' content. The techniques presented in Figure 4 are mainly characteristics from later PPC coursework, which students are encouraged to learn in order to facilitate their conversations with external partners about their given problems. Professors are easily able to perceive when students learn class contents beforehand, and use their class time as a problem-solving opportunity, in which they can clarify their doubts and facilitate their decision-making process, as discussed earlier.

In any case, the most promising results are seen in projects where the team did not postpone any tasks until the final project phase, maintaining instead a constant level of performance, especially during the Intermediate stage.

As to the correlation matrix presented in Table 2, considering non-zero p-value criteria, some concluding remarks are shown. For a $<0.1 \mathrm{p}$-value, only the relationship between time management (N3) and communication management (N4), and between the latter and the final grade (N8) could be considered uncorrelated; while for $\mathrm{a}<0.05 \mathrm{p}$-value, it is possible to disregard the correlations seen between scope (N2) and communications (N4), and between the latter and risks (N6).

Overall, it can be said that among the project planning areas, there is no significant correlation between the planning of the project's communications and the other areas of knowledge analyzed in the course, aside from stakeholder management (N5). Since stakeholder management is basically done by communicating with such actors (Project Management Institute, 2013), there is a consistency in affirming that such information correlates, although it was expected that all knowledge areas analyzed would maintain strong relationships among each other, in terms of results.

It is clear from the data that, although there is a correlation between all knowledge areas covered and the grades attributed to the project management plan (PMP), the correlation between the communication plan (N4) and the PMP (N1) is lower than between $\mathrm{N} 1$ and the other variables. The communication plan is still the only area where there is no correlation with the final project grade (N8), and presents the least significant $p$-value in relation to Intermediary and Final project grades.

Analyzing the grades attributed to groups, one can say that in all 45 PSP4 projects, the management of the project's communications was not as influential as the other areas addressed in the planning phase. This does not mean that communications planning is not important, but that the other areas analyzed have a greater impact.

There is a particular interest in evaluating the correlations between the grades attributed to the project planning elements and the overall project grade, as it is considered that a satisfactory initial planning phase results in a successful project. This is, in fact, corroborated by the results, since there is indeed a strong correlation between N1 and NG. However, which planning area has a greater impact on an optimal result? 
The initial assumption is that the areas related to better results are those linked to the project's triple constraints: scope, time and cost. They should be the closest related knowledge areas to projects' success. In the kind of project here analysed, the general grade represents project success (Mulcahy, 2013; Jugend et al., 2014; Verzuh, 2011). On the other hand, recent literature has suggested that risks, stakeholders and the resource management have a similar impact on the success of projects (Rabechini Junior \& Carvalho, 2013; Project Management Institute, 2013).

Therefore, the data shows that, from the N2 to the N6 variables, the scope (N2;r=0.65107) has a greater correlation with NG, which is coherent with the concept of the triple constraint. This result is strongly linked to the characteristics of PSP4 projects in general, in which the members of a project team are not experts in the field of knowledge related to a real organization, but are nonetheless expected to define, as precisely as possible, the assumptions and constraints in the particular case study. This is a typical issue regarding scope planning, and usually becomes a critical problem that can affect the success of a project. The evident correlations exemplify the described situation, and are consistent with the situation proposed in the PSP4 course and other courses structured around active learning.

The second highest correlation between planning elements and the overall grade is seen among the elements of risk management, time, stakeholders and communications.

These results may suggest a preponderance of the risk aspect over the time management variable, which is also consistent in the case of the evaluated projects, as the proposed schedule is seen as an external constraint, because the deadlines are set in the class syllabus itself. Conversely, risks are more dependent on the type of project, the techniques that will be applied by the team, especially since they have not yet studied the contents that they will use, as well as the difficulty in communicating with stakeholders. Finally, it is considered that the most critical steps for successful projects developed in PSP are those related to having a well-delimited scope and effective risk identification and planning.

In reality, costs are not an important element for these projects, as any delays are typically compensated with additional overtime efforts - which, in a real company, could result in higher costs, reducing the perceived success achieved by the project, or even in further limitations in scope. Therefore, time constrains become a less important factor for achieving success rates, justifying the greater emphasis given to the risk variable.

As already mentioned, quality is not incorporated into the planning phase, due to uncertainties that the lack of knowledge related to the scope of the projects causes on the initial planning process, and the fact that quality control is dependent on scope definition (Project Management Institute, 2013). However, it could be interesting to incorporate such elements of planning, as a way to test a hypothesis of overlapping problems related to scope with ones related to quality, in order to understand better the problem of restrictions on the types of projects developed by undergraduate students in active learning courses.

Analyzing the correlation between the planning variables, it is observed that the scope and risk elements are areas of knowledge with the strongest correlation with relation to the PMP grade. The strongest correlation related to scope is presented by the time variable; the communications plan is most strongly correlated to the stakeholders plan, and finally the strongest correlation with risks is seen with the time variable.

Thus, for the evaluated projects structured around an active learning format, satisfactory planning is dependent on a well-defined scope, through which an appropriate time planning is seen. The project schedule is the main input for risk analysis, which influences proper planning in a manner similar to the scope definition. Additionally, the stakeholders and communications elements have a strong relationship with each other, as stakeholder identification and engagement are seen as more influential for the success of projects than the communication planning itself.

A cluster analysis of the 45 projects was conducted, as shown in Figure 6. This procedure allowed for the identification and grouping of similar variables within a classificatory structure, according to the data of the case analyzed here. As a result, all cases are attributed to a number of homogeneous groups. Therefore, the resulting groups have the least variance among their starting elements. The analysis was performed considering the $\mathrm{N} 1$ to N8 grades, the NG grade and the technical contents covering X1 to X36.

Through this analysis, it was possible to identify two distinct groups of projects, according to Figure 6 , in which the clusters are presented as Dendrograms, also called tree graphs. The vertical axis represents groups clustered in decreasing order of similarity. The position of the arrows (Semi-Partial $R$-Squared) denotes how far these clusters are from each other, with greater distances denoting an increasing degree of dissimilarity.

The first group (cluster 1) is represented by projects 36,11,12, 27, 25, 31, 14, 10, 9 and 7 . All other projects are present in the other clusters. Table 3 presents the characteristics of the projects included in cluster 1.

The analysis of data from Table 3 shows that, of the 10 projects evaluated, half are related to public organizations and the rest to private entities, from which it is concluded that there is no dependence on the 
origin of the organization's capital. The projects represent organizations from all economic sectors, as well as all classifications in terms of company size. Finally, the projects are also not characterized specifically by their attributed grades.

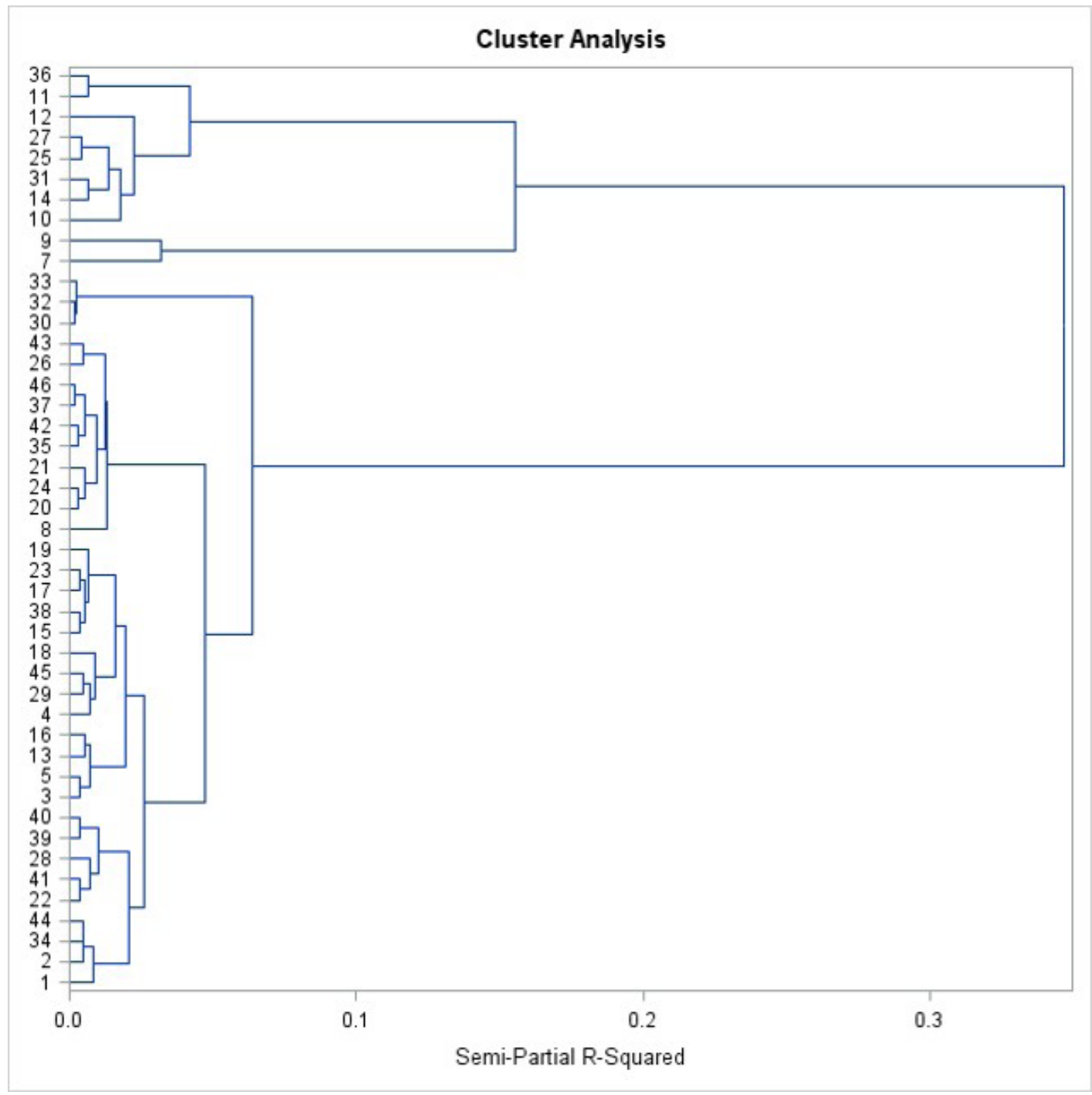

Figure 6. Dendrograms resulting from the Cluster Analysis of grades $N_{1}$ to $N_{8}$, NG and variables $X_{1}$ to $X_{36}$.

Table 3. Characteristics of elements in Cluster 1.

\begin{tabular}{cccccc}
\hline $\begin{array}{c}\text { External } \\
\text { Partner Type }\end{array}$ & Size & $\begin{array}{c}\text { Public } \\
\text { or Private }\end{array}$ & Grades & $\begin{array}{c}\text { Total } \\
\text { elements }\end{array}$ & $\begin{array}{c}\text { \% of } \\
\text { elements }\end{array}$ \\
\hline Service & Large & Public & From 7 to 8 & 5 & $13.9 \%$ \\
Industry & Large & Private & From 7 to 8 & 7 & $19.4 \%$ \\
Health & V.Small & Public & From 7 to 8 & 5 & $13.9 \%$ \\
Transportation & Large & Public & From 6 to 7 & 4 & $11.1 \%$ \\
Logistic Stock & Large & Public & From 7 to 8 & 3 & $8.3 \%$ \\
Health & Large & Public & From 8 to 9 & 3 & $8.3 \%$ \\
Industry & Small & Private & From 9 to 10 & 6 & $16.7 \%$ \\
Service & Small & Private & From 9 to 10 & 6 & $16.7 \%$ \\
Industry & V.Small & Private & From 9 to 10 & 5 & $13.9 \%$ \\
Service & Median & Private & From 8 to 9 & 5 & $13.9 \%$ \\
& & & Average & 4.9 & $13.6 \%$ \\
\hline
\end{tabular}


In an attempt to identify the representative cluster variation, we included all PPC techniques used during the projects, extracting the percentage of techniques used in relation to the entire set of tools taught during the course. The result is shown in Table 4.

Table 4. Cluster analysis.

\begin{tabular}{lccc}
\hline & Total & Cluster 1 & Cluster 2 \\
\hline Sum of the techniques used & 4.89 & 4.90 & 4.73 \\
\% of the techniques & $14 \%$ & $14 \%$ & $14 \%$ \\
\hline
\end{tabular}

It was further observed that the sum of the techniques and their percentages do not represent a difference between the clusters and the overall numbers found in the projects. Another analysis was performed in relation to the number of times that the technique was used in each cluster, in comparison to the overall number presented in the projects themselves. The mean and deviation values were calculated, in order to identify the most significant techniques for each cluster. The results are presented in Table 5.

The first analysis shown in Table 5 is related to all projects, as well as the techniques that are most commonly applied: X4, X5, X9 and X12, representing "demand forecast", “ABC curve”, "process mapping" and "control tools", respectively.

Considering the record of projects developed during the course, there has been a strong emphasis on working with demand data, which is used for both to construct an $A B C$ curve and to analyze companies' inventory data. Consequently, the processes are mapped, either to understand the company's capacity, or in order to apply inventory or process controls. Finally, there has also been a focus on building control instruments with widely used software tools, such as MS EXCEL spreadsheets or HTML modules, in order to ensure that external agents receive some effective results from the project, seeing as they have shown a great transparency in sharing their data in order to facilitate the realization of the students' projects.

It is noted that, in both clusters identified in Table 5, these variables remain significant in terms of utilization, which is consistent with the cluster analysis.

Table 5. Techniques used for each cluster.

\begin{tabular}{|c|c|c|c|c|c|c|c|c|c|c|}
\hline \multirow{2}{*}{ PPC Techniques } & \multirow{2}{*}{ Mean } & \multirow{2}{*}{ Deviation } & \multicolumn{8}{|c|}{ Most used techniques - mean } \\
\hline & & & $\mathrm{X} 4$ & X5 & X6 & X9 & $\mathrm{X} 12$ & $\mathrm{X} 13$ & $\mathrm{X} 23$ & X36 \\
\hline Total & 0.162 & 0.136 & 0.622 & 0.556 & & 0.511 & 0.444 & & & \\
\hline Cluster 1 & 0.161 & 0.136 & 0.400 & 0.500 & 0.300 & 0.600 & 0.400 & 0.400 & & 0.400 \\
\hline Cluster 2 & 0.172 & 0.136 & 0.686 & 0.571 & & 0.486 & 0.457 & & 0.314 & \\
\hline
\end{tabular}

From Table 5, it is possible to observe that the techniques $\mathrm{X} 6, \mathrm{X} 13$ and $\mathrm{X} 36$, which represent "process technology identification and planning", "capacity analysis" and "time analysis", respectively, differentiate cluster 1 from the general set of projects, as they are techniques that are more significantly represented by this cluster than in projects as a whole. These elements make it possible to characterize this cluster as representing projects where the scope is directly linked to long-term capacity planning (Vollmann et al., 2004), the purpose of which is to analyze the current capacity and suggest new production structures.

Considering that the analysis of current capacity is dependent on data linked to the manufacturing interval for each step of the process, a time analysis must be conducted by the students in order to extract it. Most commonly, these projects incorporate production bottleneck analyses (Goldratt, 2014) and also demand analyses, in order to identify a starting point for increments in capacity, and also for aligning this increase to demand forecasts. This system has, in fact, been used in various sectors, as shown in Table 3.

The second cluster differs from all other projects only due to technique X23, which represents "control / inventory management". In fact, as previously shown, 35 of 45 projects have seen the application of inventory management techniques, which constitute the second project cluster. This is indeed quite close to the general profile of the activities performed by the students during the course, only differing by one single technique. As previously mentioned, the use of $A B C$ curves is common among projects, as it already characterizes an initial analysis of inventories. 


\section{Final considerations}

This paper involves an analysis of a PBL course in the Industrial Engineering program of a Brazilian public university. Initially, the constituent elements of the course and its grading structure were presented. Unlike most research on this topic, which discusses the experiences of active learning through the use of perception and satisfaction assessment, in this research we have evaluated the relationships between the course's content and the results achieved by students in terms of formal evaluations.

In this sense, this research served to identify that there is a set of project types that is closely related to more effective results in terms of grades. These are the projects carried out in very small and small enterprises, private in nature, whose issues are related mostly to material management, even in those companies that are mostly geared towards services. It was observed that there are two major groups of projects with a focus on planning techniques and production control: analyses focused on capacity planning and those focusing on inventories. There is a set of basic techniques used in these projects, regardless of the approach: demand forecasting, $A B C$ curve, process mapping and control tools.

From a scientific perspective, the study allowed for the exploration of a few theoretical questions, as well as raising new ones. In terms of project management, it was noted that for the set of undergraduate students involved in active learning projects, the scope serves as a greater influence for success than the time variable, this being the main element of the triple constraint in the evaluated situations. In this context, it was found that proper risk planning is also more effective than a carefully defined schedule.

In the evaluated case, although project planning shows a significant effect on the final results, the delivery of the Intermediate Project was found to have the greatest impact on the final grade, among the other grades given throughout the semester. As the intermediate delivery is located chronologically in the middle of the project cycle, it appears that a planning stage, which is more evenly distributed, or more closely aligned with the middle of the cycle, would translate into better results than the traditional situation represented by the "student syndrome".

Consequently, this correlation profile, and the fact that the anchor discipline does not possess a timetable that is aligned with the PSP4 course, makes excellence a factor that is based on the students efforts in anticipating the main contents needed to solve problems presented by external partners. If they do not put in the effort to learn the content before classes, and in accordance with the partner's demands, they will probably fail to both provide results and to be evaluated as excellent by the course faculty. This result demonstrates not only the effectiveness of learning by doing, but also suggests the best outcomes of this approach when comparing groups of students with different knowledge acquisition profiles. As the research protocol was not designed for this kind of conclusion, this suggestion can be used as a hyphotesis for future investigations.

From a PPC point of view, one situation found in almost all the projects was a lack of process and management structure, and the fact that decision-making was not based on data. In a situation where data is available to management and there is a systematic manufacturing process, it is likely that the application of more sophisticated techniques would be most appropriate, even considering projects performed by students in active learning. A factor which could be approached in future studies.

From a practical point of view, planning PBL-type projects developed by undergraduate students can present some interesting aspects. Firstly, the type of company that participates as an external agent in this type of project should be considered. Some have inherent difficulties, such as the degree of bureaucratization needed in order to provide information, or the difficulty in gaining access to process operators, due to the size of the organization. The profile of the most successful projects needs to be considered, even as an initial hypothesis.

As the course is undertaken with the concept of being a co-requisite to an anchor course, the situation presented to students involves various elements of novelty. Despite reports from literature, in which PBL experiments are present as occurring in a pre-requisite format, that is, in which students have already been trained in the subjects being evaluated in ongoing projects, the results obtained here demonstrate that both the theoretical content, as well as practical results, have been successfully achieved in projects. The case described here can be used as a reference for such approaches.

An important aspect to be considered in this study refers to the possibility of the student facing different real cases. Students need to develop, in addition to the knowledge of the anchor discipline, skills in project management, teamwork, leadership, communication skills and negotiation or solving conflicts, in other words, transverse competencies are acquired and necessary for course completion. This case suggests that transversal knowledge related to scope and risk planning, such as teamwork, leadership, conflict resolution, and decision-making are more effective for this kind of project than communication skills. However, this topic demands deeper analysis, with the application of specific research protocols in future works. 
There are important limitations seen in the current research methods. On the one hand, the fact that the same professor assessed all projects may have generated a certain bias, potentially minimized by the fact that the final grades result from an average of the scores from two professors, and that there have been changes in one over the seven evaluated semesters.

From the point of view of the projects carried out by students, as discussed, there is an evaluation of aspects related to scope, time, stakeholders, communication and risks. Still, the overall grade is attributed in accordance to the quality of students' delivery. That is, "quality" is expected without first being required as one of the elements of planning. Even when quality planning and specific accomplishments are difficult to be achieved by students in a satisfactory manner, as they lack specific knowledge at the beginning of the course, it would be interesting to analyze the impact of this variable in order to investigate more critical aspects of project knowledge areas in active learning experiences.

\section{References}

Aquere, A. L., Mesquita, D., Lima, R. M., Monteiro, S. B. S., \& Zindel, M. (2012). Coordination of student teams focused on project. International Journal of Engineering Education, 28, 859. Retrieved in 24 August 2016, from http://hdl.handle.net/1822/18818

Balve, P., \& Albert, M. (2015). Project-based learning in production engineering at the Heilbronn Learning Factory. Procedia CIRP, 32 , 104-108. http://dx.doi.org/10.1016/j.procir.2015.02.215.

Bassily, H., Sekhon, R., Butts, D. E., \& Wagner, J. (2007). A mechatronics educational laboratory: programmable logic controllers and material handling experiments. Mechatronics, 179), 480-488. http://dx.doi.org/10.1016/j.mechatronics.2007.06.004.

Bezerra, E. C., Costa, A. L. M., \& Riffel, D. B. (2010). An Engineering Curriculum for the XXI century. In Proceedings of the Brazilian Congress of Engineering Education (COBENGE), Brazil.

Coyle, E. J., Jamieson, L. H., \& Oakes, W. C. (2005). EPICS: engineering projects in community sevice. International Journal of Engineering Education, 21(1), 139-150. Retrieved in 24 August 2016, from http://www.ijee.ie/contents/c210105.html

Crosthwaite, C., Cameron, 1., Lant, P., \& Litster, J. (2006). Balancing curriculum processes and content in a project centred curriculum. Education for Chemical Engineers, 1(1), 39-48. http://dx.doi.org/10.1205/ece.05002.

Damgrave, R. G. J., \& Lutters, E. (2016). Designing individual education in a group setting. Procedia CIRP, 50, 733-738. http://dx.doi. org/10.1016/j.procir.2016.04.187.

Dane, F. C. (1990). Research methods. Pacific Grove: Brooks/Cole Publishing Company.

De losRíos-Carmenado, l., López, F. R., \& García, C. P. (2015). Promoting professional project management skills in engineering higher education: project-based learning (PBL) strategy. International Journal of Engineering Education, 31(1), 184-198. Retrieved in 24 August 2016, from http://www.ijee.ie/contents/c310115B.html

Dym, C. L., Agogino, A. M., Eris, O., Frey, D. D., \& Leifer, L. J. (2005). Engineering design thinking, teaching, and learning. Journal of Engineering Education, 94(1), 103-120. http://dx.doi.org/10.1002/j.2168-9830.2005.tb00832.x.

Frank, M., Lavy, 1., \& Elata, D. (2003). Implementing the project-based learning approach in an academic engineering course. International Journal of Technology and Design Education, 13(3), 273-288. http://dx.doi.org/10.1023/A:1026192113732.

Gillette, D. D., Lowham, E., \& Haungs, M. (2014). When the hurly-burry's done, of battles lost and won: how a hybrid program of study emerged from the toil and trouble of stirring liberal arts into an engineering cauldron at a public polytechnic. Engineering Studies, 6(2), 108-129. http://dx.doi.org/10.1080/19378629.2014.944186.

Goldratt, E. M. (2014). Corrente crítica: teoria das restrições em gerenciamento de projetos. São Paulo: Nobel.

Goldratt, E. M., \& Cox, J. (2014). A meta. São Paulo: Nobel.

Jeon, K., Jarrett, O. S., \& Ghin, H. D. (2014). Project-based learning in engineering education: is it motivational? International Journal of Engineering Education, 30(2), 438-448. Retrieved in 24 August 2016, from http://www.ijee.ie/contents/c300214.html

Jugend, D., Barbalho, S. C. M., \& Silva, S. L. (2014). Gestão de projetos: teoria, prática e tendências. Rio de Janeiro: Campus-Elsevier.

Kadlowec, J., Bhatia, K., Chandrupatla, T. R., Chen, J. C., Constans, E., Hartman, H., Marchese, A. J., Lockette, P., \& Zhang, H. (2007). Design integrated in the mechanical engineering curriculum: assessment of the engineering clinics. Journal of Mechanical Design, 129(7), 682-691. http://dx.doi.org/10.1115/1.2722788.

Kolmos, A., Fink, F. K., \& Krogh, L. (2004). The Aalborg model: problem-based learning and project-organized learning. In A. Kolmos, F. K. Fink \& L. Krogh (Eds.), The Aalborg PBL model: progress, diversity and challenges (pp. 9-18). Aalborgpp: Aalborg University Press.

Lima, R. L., Carvalho, D., Flores, M. A., \& Van Hattum-Janssen, N. (2007). A case study on project led education in engineering: students' and teachers' perceptions. European Journal of Engineering Education, 32(3), 337-347. http://dx.doi.org/10.1080/03043790701278599.

Lima, R. M., Mello da Silva, J., Hattum-Janssen, N., Monteiro, S. B. S., \& Souza, J. C. F. (2012). Project-based learning course design: a service design approach. International Jornal of Services and Operations Management, 11(3), 292-313. http://dx.doi.org/10.1504/ IJSOM.2012.045660.

Lin, W., Yueh, H., \& Chou, J. (2014). Electronic pet robots for mechatronics engineering education: a project-based learning approach. International Journal of Engineering Education, 30(1), 231-239. Retrieved in 24 August 2016, from http://www.ijee.ie/contents/ c300114.html

Miranda, M. A. (2004). The grounding of a discipline: cognition and instruction in technology education. International Journal of Technology and Design Education, 14(1), 61-77. http://dx.doi.org/10.1023/B:ITDE.0000007363.44114.3b.

Mulcahy, R. (2013). PMP® Exam Prep: accelerated learning to pass PMI's PMP Exam: on you first try. Minnesota: RMC Publications Inc.

Prince, M. J., \& Felder, R. M. (2006). Inductive teaching and learning methods: definitions, comparisons, and research base. Journal of Engineering Education, 95(2), 123-138. http://dx.doi.org/10.1002/j.2168-9830.2006.tb00884.x. 
Project Management Institute - PMI. (2013). PMBOK: project management body of knowledge (5th ed.). Pennsylvania: PMI.

Rabechini Junior, R., \& Carvalho, M. M. (2013). Relationship between risk management and successful projects. Produção, 23(3), 570581. http://dx.doi.org/10.1590/S0103-65132012005000091.

Ragusa, G., \& Lee, C. T. (2012). The impact of focused degree projects in chemical engineering education on students' research performance, retention, and efficacy. Education for Chemical Engineers, 7(3), 69-77. http://dx.doi.org/10.1016/j.ece.2012.03.001.

Ras, E., Carbon, R., Decker, B., \& Rech, J. (2007). Experience management wikis for reflective practice in software capstone projects. IEEE Transactions on Education, 50(4), 312-320. http://dx.doi.org/10.1109/TE.2007.904580.

Ríos, l., Cazorla, A., Díaz-Puente, J. M., \& Yagüe, J. L. (2010). Project-based learning in engineering higher education: two decades of teaching competences in real environments. Procedia: Social and Behavioral Sciences, 2(2), 1368-1378. http://dx.doi.org/10.1016/j. sbspro.2010.03.202.

Sipper, D., \& Bulfin, R.L. (1997). Production: planning, control and integration. EUA: Mcgraw-Hill College.

Slack, N., Chambers, S., \& Johnston, R. (2009). Administração da Produção. São Paulo: Atlas.

Soares, F. O., Sepúlveda, M. J., Monteiro, S., Lima, R. M., \& Dinis-Carvalho, J. (2013). An integrated project of entrepreneurship and innovation in engineering Education. Mechatronics, 23(8), 987-996. http://dx.doi.org/10.1016/j.mechatronics.2012.08.005.

Taajamaa, V., Kirjavainen, S., Repokari, L., Sjöman, H., Utriainen, T., \& Salakoski, T. (2013). Dancing with Ambiguity Design thinking in interdisciplinary engineering education. In Proceedings of the2013 IEEE Tsinghua International Design Management Symposium (TIDMS), Shenzhen, China. http://dx.doi.org/10.1109/TIDMS.2013.6981258.

Thomas, J. W. (2000). A review of research on project-based learning. San Rafael: The Autodesk Foundation.

Tobin, K., Kahle, J. B., \& Fraser, B. J. (1990). Windows into science classrooms: problems associated with higher-level cognitive learning. New York: The Falmer Press.

Verzuh, E. (2011). The fast forward MBA in project management. Hoboken: John Wiley \& Sons.

Vollmann, T.E., Berry, W.L., Whybark, D.C., \& Jacobs, F. R. (2004). Manufacturing planning and control for supply chain management. EUA: McGraw-Hill Companies.

Yin, R. K. (2010). Case study: design and methods. Porto Alegre: Bookmann.

Zhoua, C., Chen, H., \& Luo, L. (2014). Students' perceptions of creativity in learning Information Technology (IT) in project groups. Computers in Human Behavior, 41, 454-463. http://dx.doi.org/10.1016/j.chb.2014.09.058.

Zindel, M. L., Mello da Silva, J., Souza, J. C. F., Monteiro, S. B. S., \& Oliveira, E. C. (2012). A new approach in engineering education: the design-centric curriculum at the University of Brasília-Brazil. International Journal of Basic \& Applied Sciences, 12(5), 97-102. Retrieved in 24 August 2016, from http://www.ijens.org/Vol_12_l_05/127105-8585-IJBAS-IJENS.pdf

Received: Oct. 14, 2016

Accepted: June 23, 2017 